\title{
19. REORIENTATION OF CORES USING THE FORMATION MICROSCANNER AND BOREHOLE TELEVIEWER: APPLICATION TO STRUCTURAL AND PALEOMAGNETIC STUDIES WITH THE OCEAN DRILLING PROGRAM ${ }^{1}$
}

\author{
C.J. MacLeod, ${ }^{2}$ L.M. Parson, ${ }^{2}$ and W.W. Sager ${ }^{3}$
}

\begin{abstract}
Structural and paleomagnetic studies of Ocean Drilling Program (ODP) cores are severely hampered by the fact that the recovered cores can rarely be reoriented with any degree of confidence. Although several techniques for orienting cores have been used, none is without limitations. Core orientation devices used during drilling are expensive to operate and are usually unreliable. A common alternative, used when no core orientation tools are available, is to assume that the horizontal component of the magnetization direction of the core pointed north, and thus that features may be oriented relative to this direction. However, this neglects the effects of secular variations in the Earth's magnetic field and of later tectonic rotation on the sample.

In this paper we outline a technique for core reorientation that matches distinctive inclined planar features measured on the core with their images on Formation MicroScanner and Borehole Televiewer wireline logs. It allows reorientation of structural and magnetic data, and hence the possibility of detecting vertical axis tectonic rotations using paleomagnetism. Its methodology is described and an example, from ODP Leg 135, presented to illustrate its application.
\end{abstract}

\section{INTRODUCTION}

Structural and tectonic information may be acquired from boreholes in two principal ways: either from structures measurable in the core itself, or from features detected on "images" of the borehole wall generated with specialty tools such as the Formation MicroScanner (FMS) (or its predecessor, the Stratigraphic High Resolution Dipmeter) and the Borehole Televiewer (BHTV). The former method has the advantage of direct observation but requires the difficult task of core orientation. In contrast, the latter method has the advantage of essentially continuous coverage and, because the logging tools in question are equipped with three-axis magnetometers, reliable orientation of observed features relative to geographical coordinates (e.g., Pezard and Luthi, 1988; Serra, 1989; Lehne, 1990). Although some mesoscopic features, such as bedding and fractures, can be readily measured from downhole logs (see below), many more subtle features cannot be detected. These include, for example, paleocurrent directions, the measurement of slip lineations on fracture planes, microfabrics and preferred crystallographic orientations (e.g., Moore, 1986; Lundberg and Moore, 1986), anelastic strain measurements (e.g., Teufel, 1982), study of the relative ages of different generations of veins and their diagenetic histories (e.g., Knipe, 1986; Agar, 1990), paleomagnetic measurements and other spatially anisotropic physical properties of the cores (e.g., seismic velocity, permeability, etc.). To consider these features in their spatial context, the borehole cores must be reoriented to geographical coordinates. Several techniques for core orientation can be used, each of which has its advantages and disadvantages. They are discussed briefly below.

\section{CORE ORIENTATION TOOLS}

\section{Camera Multishot Tools}

Oriented core may be obtained using a multishot orientation tool. In its simplest form, this device consists of a camera that is installed

\footnotetext{
${ }^{1}$ Hawkins, J., Parson, L., Allan, J., et al., 1994. Proc. ODP, Sci. Results, 135: College Station, TX (Ocean Drilling Program).

${ }^{2}$ Institute of Oceanographic Sciences, Deacon Laboratory, Wormley, Surrey, GU8 SUB, United Kingdom.

Department of Oceanography, Texas A\&M University, College Station, TX 77843 6331, U.S.A.
}

in a pressure housing together with a compass and pendulum, and lowered down the hole with the inner core barrel assembly. It takes photographs, at preset intervals, of the compass together with a reference line, whose orientation is determined with respect to the core. The pendulum device determines the magnitude and direction of deviation of the borehole from the vertical. Nonmagnetic drill collars must be included in the bottom-hole assembly (BHA) when the multishot tool is employed, so that the magnetic field associated with the steel drill string does not perturb the compass. Various types of reference markers are in use; these may either be grooves carved into the core with special knives set into the coring assembly (Eastman Whipstock, 1982; described in Nelson et al., 1987); or simply lines previously drawn onto core liners. The former type of marker is commonly used in the oil industry; the latter by ODP.

The more modern multishot tools used by the oil industry are designed with a nonrotating inner core barrel so that they can be used in conjunction with rotary drilling (e.g., Nelson et al., 1987; and see below); however, older multishot tools, such as the one used until recently by ODP, are simpler devices that are restricted to use with hydraulic piston coring systems (Ocean Drilling Program, 1990). The latter, therefore, have the significant disadvantage of being usable only in soft, unlithified sediments from the uppermost parts of the borehole (typically $<200 \mathrm{~m}$ below seafloor [mbsf]).

The camera multishot device has many advantages in its simplicity. Its small number of moving parts, adaptability to most gauges of core barrel, and almost real-time acquisition of results all mean that it can be widely used. However, in practice it has several, potentially serious, shortcomings that restrict its usefulness. Because of the need to use nonmagnetic drill collars in the BHA, the decision to use the multishot tool must be made before drilling begins, as it is impractical to round-trip the pipe to change the BHA at a later stage. The simple mechanical operation of the multishot tool is not infallible, and in the past, human error during installation of the system on the core barrel has resulted in misalignment of the tool by $180^{\circ}$. The reliability of the tool is critically dependent on the physical alignment between the groove or line on the core or core liner itself and the reference line photographed by the camera. This is dependent both upon the initial alignment of the tool upon assembly and on operating procedures. The camera itself is often a source of unreliability: films have a limited number of frames and often jam, batteries go dead, and the developed film is all too often uninterpretable. To avoid vibration corrupting the 
photographic record, it is normally necessary to cease coring at the time the multishot photographs are taken. This not only wastes rig time, and is therefore expensive, but increases the likelihood of the core becoming jammed or broken. It also means that it is unlikely that oriented data will be obtained from the shallowest cores at any one site, as this is a time when the drillers are anxious to proceed with spud-in lest the unsupported BHA be sheared by flexure.

For those multishot devices used with rotary drilling, torquing is a very severe problem. The very common observation that the reference grooves spiral up the core (e.g., Nelson et al., 1987) is evidence for the transmission of torque from the rotating outer to the supposedly nonrotating inner core barrel. If the spiralling is severe, the multishot photographs must be taken very frequently. Furthermore, if core recovery is less than $100 \%$, significant problems are encountered in correlating the reference grooves on individual pieces of core, whose depth is not known precisely, with the rapidly changing reference direction on the multishot photographs.

\section{Electronic Multishot Orientation Tools}

Because of the limitations of the conventional camera-based multishot orientation tools, electronic core orientation devices have recently been developed for use in the oil industry (e.g., Sperry-Sun, 1991). A prototype is also being tested by ODP (M. Storms, ODP, pers. comm., 1993). Electronic core orientation devices are equipped with solid-state magnetometers and accelerometers in the BHA that record the orientation of the reference knives as drilling is proceeding. The ODP tool employs scribing knives in the core catcher shoe that are physically aligned with a preset, software-driven electronic multishot system mounted at the top of the inner core barrel. To circumvent the uncertainties involved in matching the core scriber marks with the multishot record, a sonic device is employed that operates in conjunction with the multishot tool; this device monitors the amount of core that enters the core barrel with time. This allows the true location of any piece of core within the penetrated interval to be deduced, thus correlating the scribe mark on any particular piece of core with the appropriate reference knife orientation on the multishot record.

Electronic multishot tools overcome many, but by no means all, of the disadvantages of the camera-based tools. Nonmagnetic drill collars are still required. Their reliability is still low: the same difficulties are encountered in aligning the tool accurately during initial set-up, and torquing during operations may cause further alignment problems. Integrating the data obtained from the sonic core monitor and multishot device is not straightforward and can lead to significant uncertainties. Because of these problems, and because of the considerable expense involved in operating the tool, they are not often used by commercial operators.

Under ideal circumstances, orientation errors with either the camera-based or electronic multishot tools are claimed to be in the order of $\pm 3^{\circ}$ (Ocean Drilling Program, 1990) to $\pm 5^{\circ}$ (Nelson et al., 1987), but are typically much greater under normal operating conditions. Sager et al. (this volume), for example, found an azimuthal standard deviation of $\pm 18.6^{\circ}$ for the camera multishot tool used with piston coring at Sites 840 and 841 .

\section{Borehole Geometry Tool}

A modification of the multishot tools described above is the "borehole geometry tool" used by Schmitz et al. (1989) for core orientation in the KTB pilot well in Germany. This system makes measurements of the orientation of borehole inclination, together with the angle between the "high" side of the borehole and reference grooves scored into the core in the cutting shoe. If the borehole is deviated by $>1^{\circ}$, then the orientation of the core can be deduced. Schmitz et al. (1989) claim that gneissic foliations reoriented this way lie on average within $5^{\circ}$ of those measured on the equivalent FMS image (see below).

\section{PALEOMAGNETISM}

Ideally, the horizontal components of the stable remanent magnetization vectors of samples taken from borehole cores can be assumed to indicate north at the time of formation if the magnetization was acquired during a period of normal geomagnetic field polarity (south if during a reversed polarity period), and structures may therefore be oriented relative to this direction (e.g., McWilliams and Pinto, 1988; Dick, Erzinger, Stokking, et al., 1992). Several problems, however, are inherent in using paleomagnetism in this way, not least that a strong magnetic field emanating from the drill string frequently has the effect of partially remagnetizing the samples, giving rise to a steeply inclined magnetic component in the core. Stepwise demagnetization of the samples by alternating field or thermal techniques is often necessary, therefore, to remove this component and isolate a stable primary magnetization vector or vectors.

Some workers have had success in separating different components of the magnetization and using these to orient cores. This approach assumes that the secondary, lower stability normal polarity component that can occasionally be identified in addition to the higher stability primary magnetization vector was acquired in the direction of the present-day Brunhes normal polarity period (i.e., in the past 0.73 m.y.). Differences between the declinations of the two components may be attributed to tectonic rotations. Shibuya et al. (1991), for example, used such a technique on ODP Leg 124 core samples to postulate a $60^{\circ}$ anticlockwise rotation for the Celebes Sea during the Oligocene. This technique is somewhat restricted in its application: it usually requires either that significant rotation has occurred or that the samples be of reversed polarity, so that the Brunhes overprint can be identified and separated out reliably; and, furthermore, that any drilling-related overprint is absent or has not obscured the Brunhes component.

In addition to the problem of remagnetization, the above methods of reorienting features contain inherent errors arising from secular variations of the Earth's magnetic field. Such variations may be of considerable significance, on the order of $\pm 15^{\circ}$ in declination and inclination, particularly in those lithologies that have acquired their magnetic characteristics rapidly, such as lava flows. Typically, a period of about $10^{4}$ to $10^{5} \mathrm{yr}$ is considered sufficient to average out secular variations (Tarling, 1983); thus, slowly deposited sediment samples are considered to give more reliable indications of north than rapidly deposited sediments or lava flows.

Most important of all for our purposes, the assumption that the primary magnetization vector of the sample (if only a single component is isolated) will point due north or south can hold only if no tectonic rotation of the sample is suspected (see below). Nevertheless, under favorable circumstances, orientation of core to magnetic north using paleomagnetic data can be a simple and inexpensive technique in, for example, relatively undisturbed sedimentary sections from which paleomagnetic measurements are already being made as a matter of routine (as with ODP).

\section{COMPARISON WITH WIRELINE LOGGING DATA}

A third approach, and one which mates the directly and remotely sensed methods of acquiring structural information, is to reorient cores by comparing them with downhole images obtained from modern specialty logging tools, such as the FMS and BHTV. Data from these tools, both of which are routinely used by ODP, can be processed to generate images of the borehole wall, from small-scale variations in, respectively, resistivity and acoustic backscattering (Ekstrom et al., 1987; Zemanek et al., 1970). The resolution of the BHTV is estimated to be on the order of $3 \mathrm{~mm}$ in a 40 -cm-diameter hole (Zemanek et al., 1970), and that for the FMS, 2.5 to $5 \mathrm{~mm}$, although considerably finer features can be sensed by the latter if they have a sufficiently high-resistivity contrast (Ekstrom et al., 1987; Serra, 1989).

Both tools carry triaxial fluxgate magnetometers, so that the borehole images may be oriented to geographic coordinates, provided that 


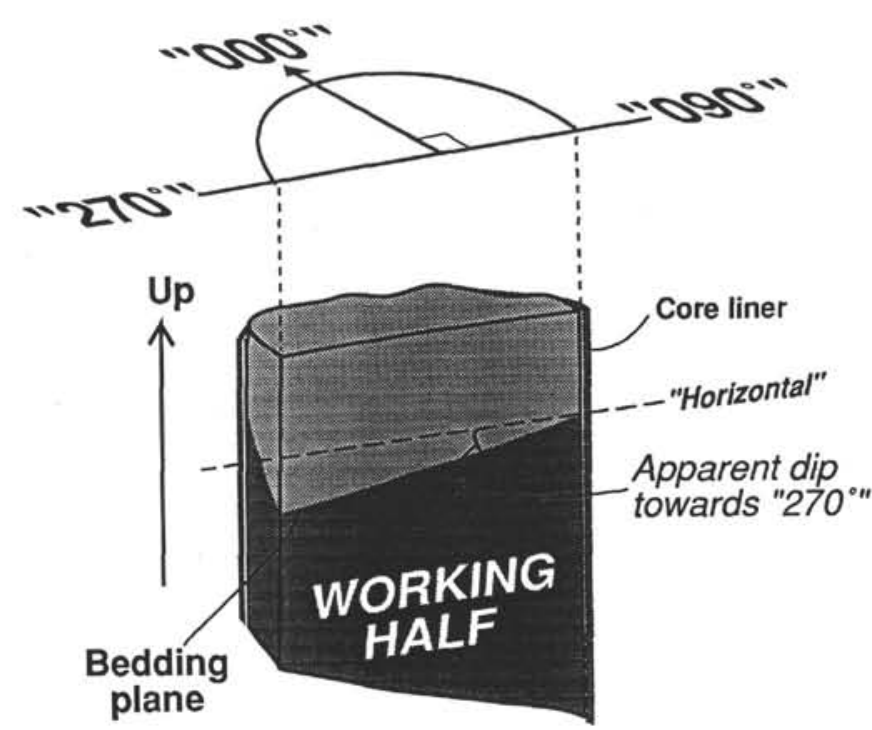

Figure 1. Definition of artificial coordinates in core, as used, for example, with Ocean Drilling Program cores. ODP cores are routinely sectioned along their axes, with one half reserved for archiving and the other used for sampling. The artificial coordinates are usually defined as shown here, with "north" lying perpendicular to the cut face of the core in the working half. Spatial information (such as the apparent dip shown here) is initially recorded relative to these coordinates before attempts are made to reorient the core to real geographical coordinates.

the formation is not too highly magnetic. Reorientation of core to the FMS and BHTV images requires the recognition of a sufficient number of orientable features that can be correlated between both core and downhole log. Regularly inclined bedding planes or consistently oriented fracture sets are ideal for this purpose. A 1:1 correlation between features in the cores and on the images is desirable; in practice, however, this may be possible only for certain intervals of the borehole. Note that the substantially larger external diameter of the borehole compared to that of the core (typically $25 \mathrm{~cm}$ as opposed to $8 \mathrm{~cm}$ ) means that the oblique features will have much greater vertical extents on the FMS and BHTV images than on the cores or core photos; only the strike of the feature will appear at the same depth (Adams et al., 1990). In addition, it is important to realize that in areas of less than $100 \%$ recovery, most operators (including ODP) make the assumption that all recovered core comes from the top of the cored zone, when in reality it could have come from anywhere within the cored interval. This problem will be addressed to some extent in the future with the development of ODP's sonic core monitor (discussed above).

The technique by which reorientation of core using FMS and BHTV images is conducted is described in more detail below.

\section{Measurement of Planar Features in Cores}

Several methods of measuring planar features in cores are in use. The most accurate and sophisticated way is to use a goniometer, either mechanical (e.g., Nelson et al., 1987) or electronic (Bergosh et al., 1985). Nelson et al. (1987) claim a reproducibility error of $\pm 2.75^{\circ}$ in azimuth and $\pm 0.75^{\circ}$ in dip for the mechanical instrument, and about half of that with the electronic device.

An alternative technique, less precise but usable when no specialized equipment is available, is to measure the features by hand by combining apparent dip measurements. This technique has been used successfully on many occasions with ODP cores (e.g., Taira, Hill, Firth, et al., 1991; Parson, Hawkins, Allan, et al., 1992; Gillis, Mével, Allan, et al., 1993), but it is equally applicable to any core. ODP cores, which are recovered in plastic liners, are routinely sectioned along the
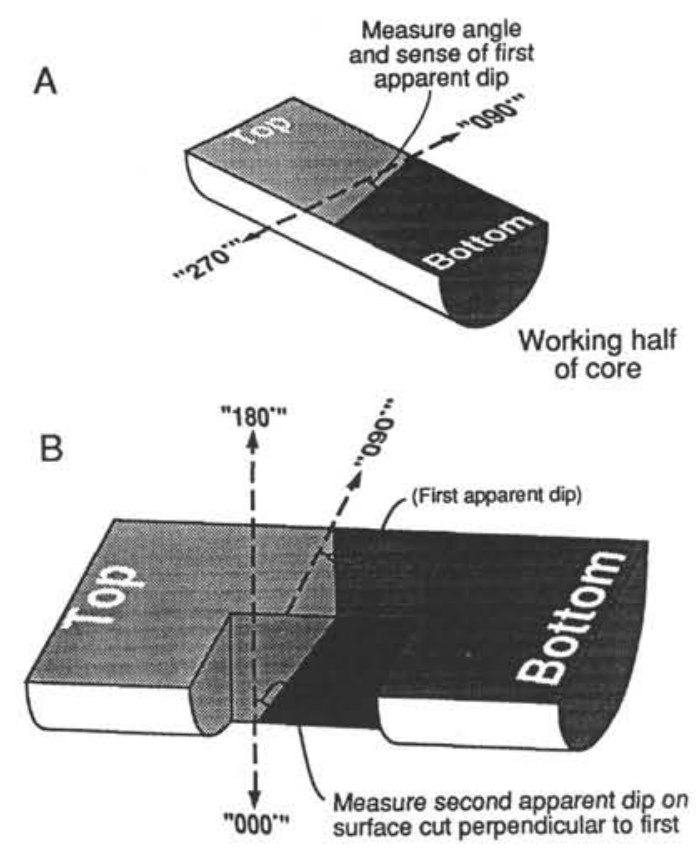

Figure 2. Method of determining bedding direction in cores (relative to the core-liner coordinates) by the combination of two apparent dip measurements. A. The apparent dip and direction of apparent dip are measured on the cut ("090"-" 270 ") surface of the core. B. A quarter-round of core is removed perpendicular to the previous face to expose an " 000 "-" 180 " section. A second apparent dip is measured on this surface. The two apparent dips are combined into a composite dip and strike using stereographic techniques.

axis of the core. One half of the sectioned core is reserved for archiving, and the other is used for sampling purposes. The plastic core liners have orientation marks, and a nominal "core liner north," which has no geographic significance, is chosen relative to these marks. Usually this "north" is taken to lie in the working half of the core, perpendicular to the plane along which the core was split (Fig. 1). Standard procedure is initially to make all structural and paleomagnetic measurements relative to these synthetic coordinates, before any attempt to reorient them to geographical coordinates. Note that, although most sections of soft unlithified sediment recovered by hydraulic piston coring techniques should be contiguous within any one core barrel, in those more lithified formations recovered by rotary coring, in which recovery is usually much less than $100 \%$, the core is broken up by the drilling process and each individual piece is rotated independently of its neighbors. Consequently, pieces will have randomly oriented true azimuths.

In unlithified sediments, dips and strikes of bedding are made by the measurement of two apparent dips: one on the cut ("east-west") surface of the core, and another on a surface perpendicular to this, made by removing a quarter round of core using a scoop or some such apparatus (Fig. 2). With a moderate amount of practice these measurements can easily be made to the nearest degree. The two apparent dips are combined into a single dip and strike (relative to the synthetic coordinates) using simple stereographic techniques. Significant errors in the strike measurement in near-horizontal bedding are to be expected by this method, but these decrease rapidly as the dip increases (Fig. 3). Dip estimates are much more well constrained and should be no worse than $\pm 1^{\circ}$ to $2^{\circ}$. In many cases planar features lie at the ends of core pieces, in which case their dips and strikes can be measured directly.

In lithified but coherent cores, synthetic orientations can be measured according to a similar principle, by sawing the core to obtain the second apparent dip surface. Often a horizontal surface may be cut and a strike measurement obtained instead or as well, and this con- 


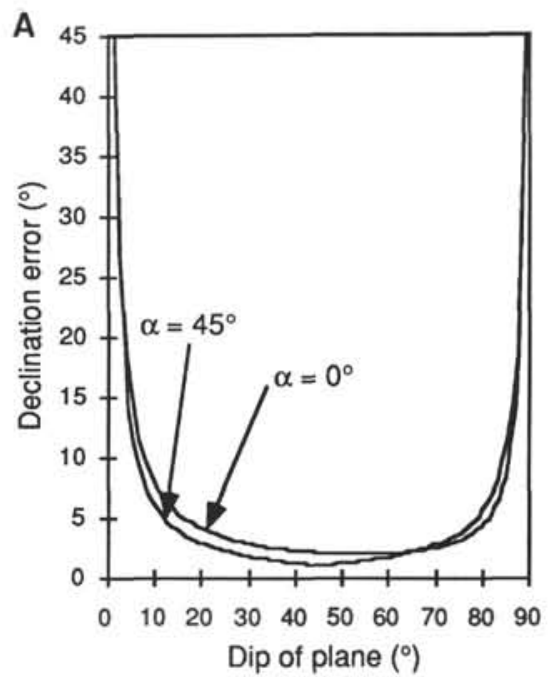

Figure 3. Estimation of the errors inherent in the calculation of the orientation of a plane from the combination of two orthogonal apparent dip measurements, assuming that each apparent dip can be measured to the nearest degree. A. Declination error as a function of dip of the plane. Curves are calculated for a plane dipping toward one of the apparent dip axes (labeled $\alpha=0^{\circ}$ ), and for a plane dipping at $45^{\circ}$ to these axes (labeled $\alpha=45^{\circ}$ ). Note the extremely high potential declination errors for near-horizontal strata, but much lower errors as the dip of the plane increases. B. Calculation of curves given in Figure $3 \mathrm{~A} . \delta_{\mathrm{e}}$ and $\delta_{\mathrm{s}}$ are the two orthogonal apparent dips, here shown relative to core liner "east" and "south," respectively, and $\delta_{x}$ is the true dip of the plane; $\alpha$ is the declination of the plane, for convenience measured here from "east." The maximum declination error is calculated as either $\alpha-\alpha$ ' or $\alpha-\alpha^{\prime \prime}$, where $\tan \alpha^{\prime}=\tan \left(\delta_{\mathrm{s}}+1\right) / \tan \left(\delta_{\mathrm{e}}-1\right)$ and $\tan \alpha^{\prime \prime}=\tan \left(\delta_{\mathrm{s}}-1\right) / \tan \left(\delta_{\mathrm{e}}+1\right)$. The two curves given in Figure $3 \mathrm{~A}$ are for $\alpha=0^{\circ}$ and $\alpha=45^{\circ}$; intermediate values of $\alpha$ will yield comparable results.

strains much better the orientation of the feature: the estimated uncertainty in strike azimuth being reduced to no more than $\pm 1^{\circ}$ to $2^{\circ}$.

\section{Measurement of Planar Features on FMS and BHTV Images}

The FMS and BHTV carry triaxial fluxgate magnetometers that allow orientation of their resistivity and acoustic backscatter measurements respectively. The accuracy of the magnetometers is claimed to be in the order of $\pm 2^{\circ}$ (Schlumberger 1986), that is, better than the manual measurement of features in the core (Fig. 3), although the possibility of systematic errors in or adjacent to highly magnetic formations (e.g., oxide gabbros: Goldberg et al., 1992) should be noted.

Processed FMS and BHTV images are displayed on a rectangular plot that represents an unwrapped image of the inside of the borehole. The $x$-axis, equivalent in width to the circumference of the borehole, gives the azimuth of the image relative to true north, and the $y$-axis, the borehole depth. Inclined, planar features intersecting the borehole will appear as sinusoidal traces on plots (Fig. 4). Calculation of the orientations of planes is made simply by measuring the azimuth of the lowest point of the sinusoidal feature to obtain the dip direction, and working out the arctangent of the difference in height of the top and bottom of the trace (h) divided by the borehole diameter (d) (Fig. 4). Acetate overlays with sinusoids of known dip may be constructed for use with hard-copy images, but they are specific to given vertical and horizontal scales and borehole diameter. Software is now commonly in use that allows the matching of sinusoids interactively with computer-displayed images (e.g., the Schlumberger "FMS Image Examiner": Serra, 1989; Bourke et al., 1989; or the "BHTV Image" interactive work station: Barton et al., 1990). Errors introduced at this stage of the process, particularly with the computer-picked sinusoids, are considered to be minimal.

The BHTV presents coverage of $100 \%$ of the borehole wall; in contrast, an FMS image from a single pass of the tool covers approximately $40 \%$ of the surface of the borehole only (for the ODP four-pad tool), depending upon the hole diameter. Whereas sinusoidal features can be observed unambiguously on BHTV images, on FMS plots they are discontinuous and must be interpolated between the individual pad traces. To minimize errors resulting from false correlations, two passes of the FMS tool are often made and their resistivity images merged into a single plot to increase the effective coverage of the borehole (although in practice the tool tends to follow the same path
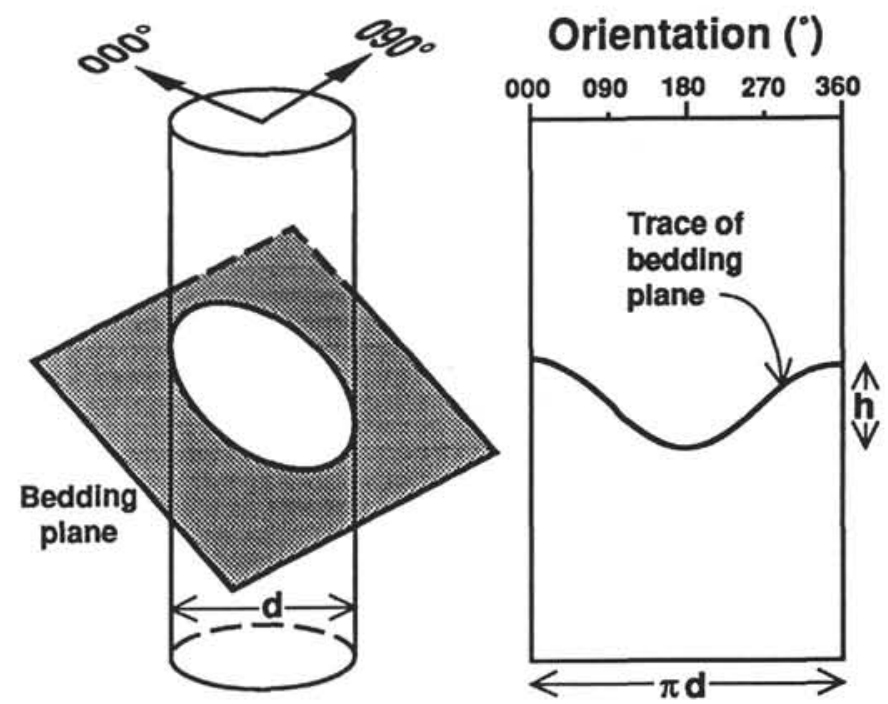

Figure 4. Sketch of a hypothetical bedding plane intersecting a borehole, and the appearance of such a plane on an FMS- or BHTV-style plot. The FMS and BHTV data are usually presented in the form of an unwrapped cylinder; planes intersecting the borehole will appear, therefore, as sinusoids on plots. The dip of the plane is calculated as the arctangent of the height of the trace on the borehole image (h) divided by the diameter of the hole (d). 
if the borehole is even slightly elliptical; see, for example, MacLeod and Pratt, this volume).

In addition to the manual picking of dips from FMS images, whether by hand or with a work station, FMS data from the four-pad tool can be processed to yield plots of bedding dip and strike analogous to those produced by the Dual Dipmeter (or Stratigraphic High Resolution Dipmeter) Tool. In essence, this processing involves the comparison and correlation of resistivity responses between the four pads over a given interval of the borehole. The resistivity response of a dipping feature with characteristic signature will be recorded by the pads at different depths, and from this its dip and strike can be calculated. A number of techniques for the computation of dips from the resistivity data are in use, based upon different methods of correlation between pads. The techniques, and interpretation of their results, are discussed in detail in Schlumberger (1986). However, it is pertinent to note that most of these methods (including the standard "Mean Square Dip" computation) involve calculation of a single "best fit" average dip measurement over a given search interval, typically $4 \mathrm{ft}(1.2 \mathrm{~m})$; therefore, it is most suitable for regular, planar-bedded sedimentary sequences. Fractures, veins, and smaller scale bedding features that may be visible in the core and on the FMS images are not likely to be discriminated by such computational techniques.

\section{Methodology of Core-log Integration}

If an inclined planar feature visible on FMS or BHTV images of an interval of borehole can also be recognized in core from the same interval, then that section of core can be reoriented to geographic coordinates. Not only are the inclined features reoriented (be they bedding, joint planes, or whatever), but also all other cryptic features within the same contiguous core piece that cannot be imaged by the logging tools, including fault slip lineations, microfabrics, paleomagnetism, and so forth. Systematic deviations of, for example, restored, cleaned paleomagnetic declinations away from north may be indicative of tectonic rotations about vertical or inclined axes (see below).

The principle of core reorientation is illustrated in Figure 5. It is demonstrated in practice in the example given below, based upon the following methodology. The core or core photographs are compared with the FMS records from the same interval. One $9.5-\mathrm{m}$ core is a convenient length for the initial comparison. Distinctive lithologic features (e.g., turbidite horizons or groups of horizons) may allow beds to be matched directly on a 1:1 basis with the equivalent resistivity variations on the FMS records. In most instances recovery is less than complete, in which case the depth of the feature in the core and the equivalent horizon on the logs will not be identical, and a correction will need to be made. In this regard it is useful to distinguish "core depth" from "log depth."

It is not usually possible to correlate many pieces of core with the FMS on a 1:1 basis. More often, a core piece may only be constrained to lie within a particular depth interval. If no definite matches have been made then the size of this window will depend upon the amount of core that is missing and the position of the particular core piece within the recovered material.

Bedding orientations are obtained both from the automatic "dipmeter" processing of the FMS resistivity data, and from horizons picked manually from the FMS images using log analysis software. Use of the latter allows faults and fractures to be recognized and measured in addition to the sedimentary bedding; furthermore, it enables individual bedding planes to be measured, rather than the average bedding orientation per unit interval that is obtained from the dipmeter computation.

Magnetization directions of discrete samples of core are oriented relative to core-liner coordinates. Bedding and/or fracture planes from the same contiguous core piece are measured relative to the same coordinates. These planes are then compared with FMS bedding and fault orientations taken from the window of possible log depths.
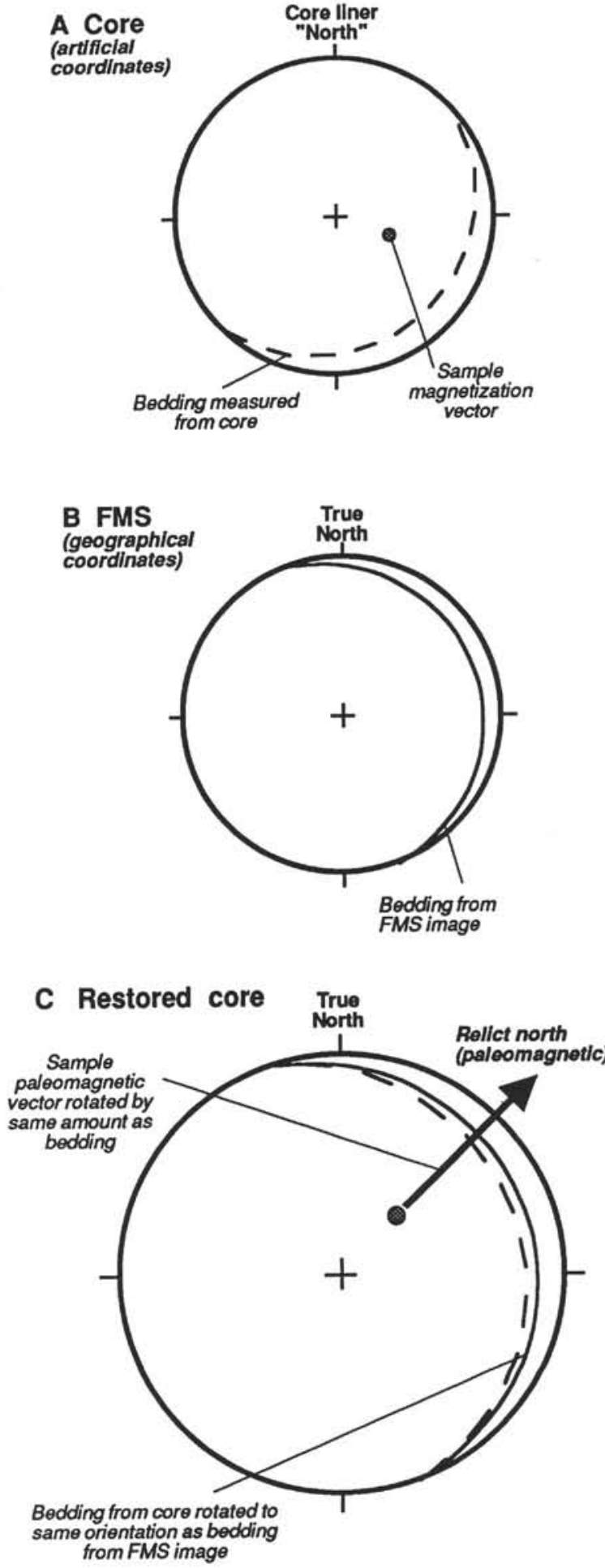

Figure 5. A. Sedimentary bedding measured from the core (Figs. 1-2), together with the cleaned stable remanent magnetization vector from a sample from that same contiguous core piece, are plotted relative to core liner coordinates (lower hemisphere, equal-angle projection). B. The true sedimentary bedding dip and dip direction are known from FMS or BHTV images from the same interval. C. The core bedding is rotated, therefore, to the true bedding orientation and the sample magnetization vector is rotated by the same amount. The deviation of the restored magnetization vector from north (or from south if the sample is of reversed polarity) may be the result of a tectonic rotation. 
In most cases, several FMS bedding measurements are taken from the relevant depth interval (which will typically be a few meters). Ideally, these bedding orientations will be consistent, and consequently there will be no ambiguity as to an appropriate dip direction to use for reorientation of the core bedding. If the FMS data show a range of dip directions, then strict criteria must be applied to choose the most appropriate direction to use. If fractures have been measured in the core and with the FMS work station, then the angular relationship between bedding and cross-cutting fractures provides powerful constraint on the most appropriate dip direction to use; indeed, it is often more appropriate to reorient a piece of core relative to a fracture or set of fractures than to sedimentary bedding. Stereographic projections of the bedding and fault data (relative to core-liner coordinates) from each contiguous core piece and of the relevant FMS data (relative to true north) can be compared to aid the reorientation process. Dip magnitudes as well as directions are also considered: those dip picks that differ greatly from the core bedding dip are deemed to be inappropriate and are discarded. In those intervals of the borehole most obviously affected by faulting, we have found the dips made by the automatic dipmeter to be less consistent than those picked by hand from the FMS work station; in such instances the latter were generally preferred.

If the spread of dip orientations that meet the above criteria is small, then the core measurements are restored to the most representative FMS dip reading. If, however, the FMS dip direction data from the relevant interval are still inconsistent, and fault data do not allow a unique direction to be constrained, no unique solution can be determined. In this case none is chosen and the core piece is therefore not reoriented.

In practice, definite correlations between inclined features in core and on log images may only be possible at certain intervals within the borehole. This does not necessarily restrict the usefulness of the technique; in determining the magnitude and timing of tectonic rotations, for example, it is better to obtain accurately restored magnetic declinations from fewer discrete, well-constrained intervals in the borehole than to attempt to make correlations of dubious reliability from the entire depth range. The principal uncertainty in the technique is likely to be in making inappropriate matches between features in the core and on FMS or BHTV logs; thus, as large a number of reorientations as possible should be made from the better constrained intervals (typically regular, parallel sedimentary bedding over a depth range of several meters to tens of meters) to minimize spurious matches.

A computer program has recently been developed for the KTB drilling project to aid the correlation of features between core and logs (Kessels and Kück, 1992). It uses a similar methodology to that outlined here, matching the dip, azimuth, and relative depth of each feature in any one core piece against features within a given search interval on the borehole image. It places the core features in every possible position, calculates the mismatch of the three parameters in each case, and takes as its preferred solution the depth and orientation with the minimum residual error. With their program, the authors claim a mean standard deviation for the restored azimuths of $\pm 9^{\circ}$ with respect to the best results obtained using manual reorientation techniques.

The declination errors inherent in the manual reorientation technique described herein are estimated to be typically on the order of $\pm 8^{\circ}$ to $12^{\circ}$ (at 2 standard deviations) for hand-measured dips (depending on whether a dip and a strike or two apparent dips are used to define the core measurement; the stated figure is for a plane dipping at $15^{\circ}$ ), or $\pm 7^{\circ}$ to $8^{\circ}$ using an electronic goniometer. These figures assume an uncertainty of $\pm 2^{\circ}$ in the FMS/BHTV magnetometer measurement, and $\pm 3^{\circ}$ in the paleomagnetic measurement. For further discussion of the most appropriate statistical treatment of the errors involved, see Sager et al. (this volume).

The method of core orientation described herein is not restricted to use with ODP but can potentially be applied to any core for which logging data are available, and at any stage; for example, if the need for obtaining oriented material was not appreciated at the time drilling took place, and a multishot tool was therefore not employed or not available. It is also an extremely inexpensive means of acquiring oriented core when compared with the operating costs of either the camera-based or electronic multishot tools, and it does not suffer the disadvantage of the older style multishot orientation tool of being restricted in use to soft sediment.

\section{EXAMPLE}

The Lau Basin is a triangular-shaped, active, backarc marginal basin in the southwestern Pacific, forming at the leading edge of the Indo-Australian Plate as it overrides the subducting Pacific Plate (Fig. $6 \mathrm{~A}$ ). The basin lies between a north-trending remnant arc (the Lau Ridge) to the west and a north-northeast-trending active island arc/ forearc complex (the Tonga Ridge) in the east (Fig. 6B). It is clear that the extent of opening of the basin has been greater in the north-central part than in the south, and various models have been proposed that involve rifting and translation of the active and remnant arcs during basin formation: either of the Lau Ridge away from the (essentially static) Tonga Ridge (Packham, 1978; Herzer and Exon, 1985) or vice versa (Karig, 1970; Hawkins et al., 1984). All of these hypotheses require the bulk rotation of either one or both of the Lau and Tonga ridges as the Lau Basin opened.

We now think, following the ODP drilling (Parson, Hawkins, Allan, et al., 1992; and see papers in this volume), that the opening history of the basin involved a protracted period of attenuation and rifting of the original Lau/Tonga protoarc before initiation of the backarc seafloor spreading known to be active at the present day (e.g., Collier and Sinha, 1990; Parson et al., 1990). Parson and Hawkins (this volume) suggest that the backarc spreading axis (now represented by the Eastern Lau Spreading Center) formed at approximately 5.5 Ma in the vicinity of the Peggy Ridge and propagated southward through the attenuated arc crust, "unzipping" the Lau and Tonga ridges as it did so. This arc rifting process is continuing today at the Valu Fa Ridge. In the past 1 to 2 m.y., a second propagating rift (the Central Lau Spreading Center) has formed and is moving rapidly southward through the existing backarc crust, at the expense of the Eastern Lau Spreading Center (Parson et al., 1990; Parson and Hawkins, this volume).

Leg 135 drilled six sites in the western part of the Lau Basin, between the Lau Ridge and the active Lau spreading centers, and two on the Tonga platform/forearc (Fig. 6B). The latter two sites were of particular interest with regard to the above debate; specifically, to attempt to determine whether or not the Tonga Ridge had rotated clockwise during opening of the Lau Basin. Site 841 was drilled in approximately $4800 \mathrm{~m}$ of water on the upper trench slope of the Tonga forearc, through late Eocene to Holocene turbidites and oozes into a low-K rhyolitic arc complex (Parson, Hawkins, Allan, et al., 1992). Seismic reflection data indicate recent faulting in this part of the forearc, and Site 841 is the sole site drilled during Leg 135 at which we have evidence for significant faulting and disruption of the succession. Tilting of the sediments, even close to seafloor, has been such that dips in excess of $30^{\circ}$ are not uncommon (MacLeod, this volume). This tectonic tilting makes the site ideal for application of the reorientation technique described herein, both to reorient the paleomagnetic measurements (to address the broader scale tectonic questions outlined above) and the hundreds of small-scale structures and veins measured from the core. The relatively steep dip to many of the sedimentary strata minimizes those errors because of the manual measurement of core dips (cf. Fig. 3).

In Table 1 we present a subset of the raw bedding and magnetic data from Hole $841 \mathrm{~B}$, together with the FMS dip picks from the corresponding intervals of Hole $841 \mathrm{C}$, to illustrate how the reoriented data are derived. In total, 120 cleaned paleomagnetic data and 127 faults have been reoriented using the method described herein (Figs. 7-8). These data are discussed in detail by Sager et al. (this volume) and MacLeod (this volume), respectively.

The paleomagnetic data plotted in Figure 7 have not been corrected for bedding dip. Application of conventional bedding correc- 
Table 1. Example from Hole 841B (490-550 mbsf) illustrating the stages involved in core reorientation.

\begin{tabular}{|c|c|c|c|c|c|c|c|c|c|}
\hline \multirow[b]{2}{*}{$\begin{array}{l}\text { Core, section, } \\
\text { interval }(\mathrm{cm})\end{array}$} & \multirow[b]{2}{*}{$\begin{array}{l}\text { Depth } \\
\text { (mbsf) }\end{array}$} & \multicolumn{6}{|c|}{ Core coordinates } & \multicolumn{2}{|c|}{$\begin{array}{l}\text { Geographical } \\
\text { coordinates }\end{array}$} \\
\hline & & $\begin{array}{l}\text { App. } \\
\text { dip } 1\end{array}$ & $\begin{array}{l}\text { App. } \\
\text { dip } 2\end{array}$ & $\begin{array}{l}\text { App. } \\
\text { str. }\end{array}$ & $\begin{array}{l}\text { Aux. } \\
\text { dip }\end{array}$ & $\begin{array}{l}\text { Dip } \\
\text { dirn. }\end{array}$ & $\begin{array}{c}\text { SMV } \\
\text { (dec., inc.) }\end{array}$ & $\begin{array}{c}\text { FMS } \\
\text { dip dim. }\end{array}$ & $\begin{array}{c}\text { SMV } \\
\text { (dec., inc.) }\end{array}$ \\
\hline \multicolumn{10}{|l|}{ 135-84IB- } \\
\hline $35 \mathrm{R}-3,123$ & 491.37 & $18 \mathrm{R}$ & $28 \mathrm{~T}$ & - & 32 & "149" & "050.3". -29.9 & 103 & $004.3 ;-29.9$ \\
\hline $37 \mathrm{R}-1,76$ & 507.16 & $27 \mathrm{~L}$ & $2 \mathrm{~T}$ & - & 27 & $" 266 "$ & $" 140.0 ",-34.2$ & 136 & $010.0 ;-34.2$ \\
\hline $37 \mathrm{R}-3,119$ & 510.59 & $24 \mathrm{~L}$ & - & "013" & 26 & "283" & $" 162.5 ",-45.4$ & 136 & $015.5 ;-45.4$ \\
\hline $37 \mathrm{R}-4,90$ & 511.80 & $25 \mathrm{~L}$ & $11 \mathrm{~T}$ & - & 27 & $" 247 "$ & $" 171.6 ",-55.4$ & 134 & $058.6 ;-55.4$ \\
\hline $38 \mathrm{R}-1,45$ & 516.55 & $21 \mathrm{R}$ & $11 \mathrm{~T}$ & - & 23 & $" 117 "$ & "005.4",-18.4 & 117 & $005.4 ;-18.4$ \\
\hline $38 \mathrm{R}-1,57$ & 516.67 & $31 \mathrm{R}$ & $6 \mathrm{~T}$ & - & 31 & "100" & "012.3", -22.0 & 115 & $027.3 ;-22.0$ \\
\hline $38 \mathrm{R}-2,135$ & 518.95 & $12 \mathrm{R}$ & - & $" 000 "$ & 12 & "090" & "009.7", -40.9 & 124 & $043.7 ;-40.9$ \\
\hline $38 \mathrm{R}-3,8$ & 519.18 & $23 \mathrm{R}$ & $4 \mathrm{~T}$ & - & 23 & "099" & $" 337.7 ",-36.7$ & 134 & $012.7 ;-36.7$ \\
\hline $38 \mathrm{R}-4,21$ & 520.81 & I8R & $5 \mathrm{~T}$ & - & 19 & "105" & $" 001.4 ",-54.9$ & 134 & $030.4 ;-54.9$ \\
\hline $40 \mathrm{R}-1,50$ & 535.80 & $8 \mathrm{~L}$ & $8 \mathrm{~T}$ & - & 11 & " $225 "$ & $" 171.6 ",-20.8$ & 134 & $080.6 ;-20.8$ \\
\hline $40 \mathrm{R}-1,120$ & 536.50 & $13 \mathrm{~L}$ & $8 \mathrm{~B}$ & - & 15 & "301" & $" 187.9 ",-57.9$ & 125 & $011.9 ;-57.9$ \\
\hline $40 \mathrm{R}-2,49$ & 537.22 & $29 \mathrm{~L}$ & 3B & - & 29 & "275" & "189.9", -39.8 & 124 & $038.9 ;-39.8$ \\
\hline $40 \mathrm{R}-3,34$ & 538.41 & $32 \mathrm{~L}$ & 0 & - & 32 & $" 270 "$ & $" 196.3 ",-34.7$ & 124 & $050.3 ;-34.7$ \\
\hline $41 \mathrm{R}-1,40$ & 545.40 & $21 \mathrm{~L}$ & $27 \mathrm{~B}$ & - & 33 & "323" & $" 219.7 ",-54.8$ & 163 & $059.7 ;-54.8$ \\
\hline $41 \mathrm{R}-2,34$ & 546.84 & $30 \mathrm{R}$ & - & "026" & 33 & $" 116 "$ & $" 332.1 ",-56.4$ & 161 & $017.1 ;-56.4$ \\
\hline $41 \mathrm{R}-3,23$ & 548.23 & $29 \mathrm{~L}$ & $27 \mathrm{~B}$ & - & 37 & "313" & "202.6", -57.2 & 147 & $036.6 ;-57.2$ \\
\hline
\end{tabular}

Notes: The raw sedimentary bedding measurements are recombined, matched with the FMS bedding directions, and the corresponding magnetization directions corrected. The reoriented magnetic data are a subset of those plotted in Figure 7. "B," "R," "T," and "L" suffixes refer to apparent dip directions toward the temporary core-liner coordinates "000," "090," "180," and "270," respectively. Paleomagnetic data (from the same core pieces) are stable, assumed primary, magnetization directions isolated after alternating-field demagnetization (see Sager et al., this volume). All these paleomagnetic and auxiliary bedding measurements are made relative to core-liner coordinates and are enclosed by quotation marks. The true dip directions of the sediments are obtained from FMS data from the same interval of adjacent Hole 841C. From these data, corrected magnetic azimuths are calculated (see final column) and plotted in Figure 7. App. dip = apparent dip, App, str. $=$ apparent strike, Aux. dip = auxiliary (recombined) dip, dip dirn. $=$ dip direction of sedimentary bedding (relative to the core-liner), SMV = sample magnetization vector, dec. = declination, and inc. $=$ inclination.

tions, about either strike-parallel or trench-parallel axes, reduces both the declination and inclination of the mean magnetization vector by a few degrees (see Sager et al., this volume). It is beyond the scope of this paper to discuss the most appropriate bedding correction to use under the present circumstances, given the difficulty in constraining the relative contributions of tectonic tilting vs primary depositional dip to the overall dip of the sediments; the reader is instead referred to Sager et al. (this volume).

We interpret the northeasterly mean declination in Figure 7 to result from the clockwise rotation by tectonic means of Site 841 . Paleomagnetic results from unlithified sediments at both Leg 135 sites on the Tonga Ridge (i.e., Sites $840-841$; Fig. 6B) that were oriented using the ODP multishot tool also show statistically significant clockwise deviations of magnetic declinations away from true north (Sager et al., 1991, this volume). These data confirm the FMS-oriented results given here, supporting the suggestion that clockwise rotation of the entire Tonga Ridge has occurred. They contrast markedly, however, with paleomagnetic results from the western part of the Lau Basin (Sites 834-839; Fig. 6B), which exhibit consistent northerly declinations (Sager et al., 1991) and therefore do not appear to have suffered comparable tectonic rotations.

In Figure 8, we present structural data from Hole 841B cores, reoriented following the procedure described for the paleomagnetic data above. Both normal and reverse faults, with millimeter- to centimeter-scale displacements, are abundant throughout Hole 841B (MacLeod, this volume), but most appear to be too small to be visible on the FMS records. Except in very rare instances, it is not possible to obtain kinematic information from faults detected by the FMS; hence, valuable information is gained by reorienting structural data from the core in this way. In Figure 8 , we are accordingly able to distinguish between normal (Figs. 8A-8B) and reverse faults (Figs. $8 \mathrm{C}-8 \mathrm{D}$ ). Both fault types show a near trench-parallel mean strike (we do not place much emphasis on the slightly more N-S strike of the reverse faults, given their shallow dip and smaller data set), but differ significantly in dip between the shallowly dipping reverse faults and near-vertical normal faults. The structural implications of the fault data are discussed in detail by MacLeod (this volume).

\section{DISCUSSION}

The lack of orientation information is a serious handicap to many different studies of borehole cores, and hinders the integration of core data with broader scale geological information obtained from other sources. Although specialist core orientation tools exist, they are expensive to operate and tend to be unreliable. Other reorientation techniques have serious flaws that restrict their usefulness. We have shown here, however, that it is not only possible but practical to reorient cores to an acceptable degree of accuracy by comparing planar features in the cores with their representations on FMS and BHTV downhole images.

Applications of this technique are many. Particularly valuable is the ability to detect tectonic rotations from anomalies in restored paleomagnetic declinations. Land-based paleomagnetic studies have shown that tectonic rotations on a variety of scales are a integral part of the deformation process in continental tectonic belts (e.g., Kissel and Laj, 1989, and papers therein). It is clear that such rotations do not only occur on land, nor are they restricted to continental crust: structural and paleomagnetic studies of ophiolites, for example, have shown that ocean-floor rotations about subhorizontal, subvertical, or oblique axes are common in many tectonic environments (e.g., Allerton and Vine, 1987; Bonhommet et al., 1988). Nevertheless, although vertical axis rotations have been postulated from analyses of magnetic lineations (e.g., Tamaki and Larson, 1988; Searle et al., 1989) and seamount magnetic anomalies (Sager and Pringle, 1987), they have largely been inferred by indirect means only. This is mostly for practical reasons, principally because of the difficulty of recovery and orientation of samples from the seafloor.

The technique outlined here offers one of the first direct means of detecting vertical axis tectonic rotations (or components of rotation) in the oceanic domain. This should, in turn, allow better understanding 
A

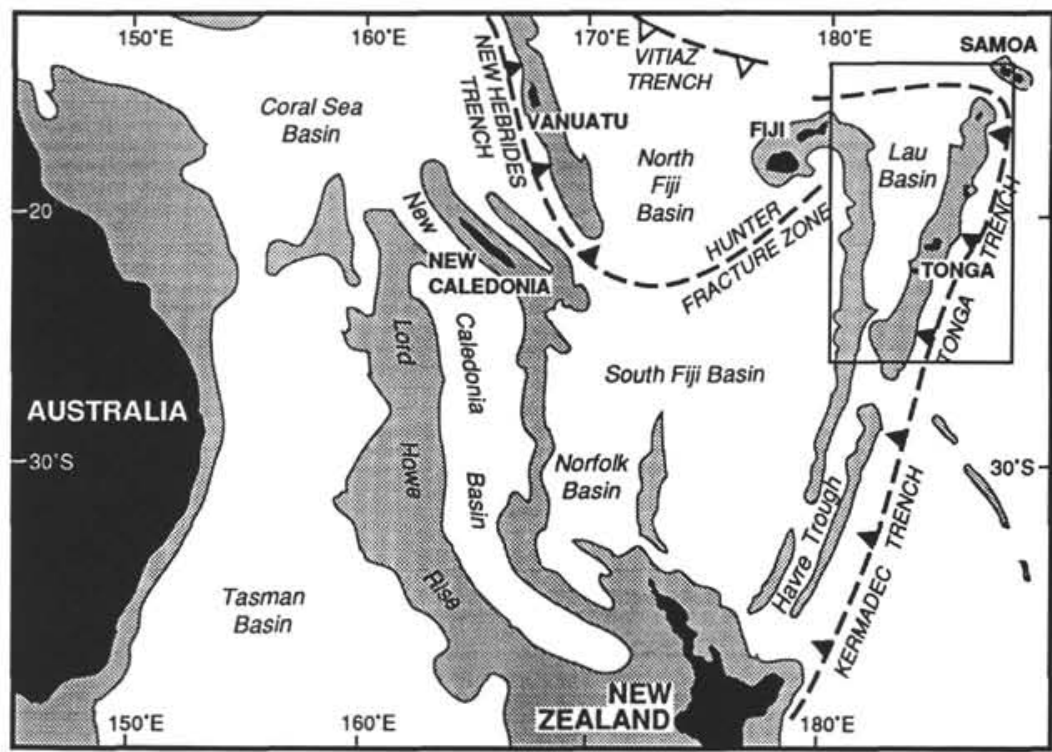

B
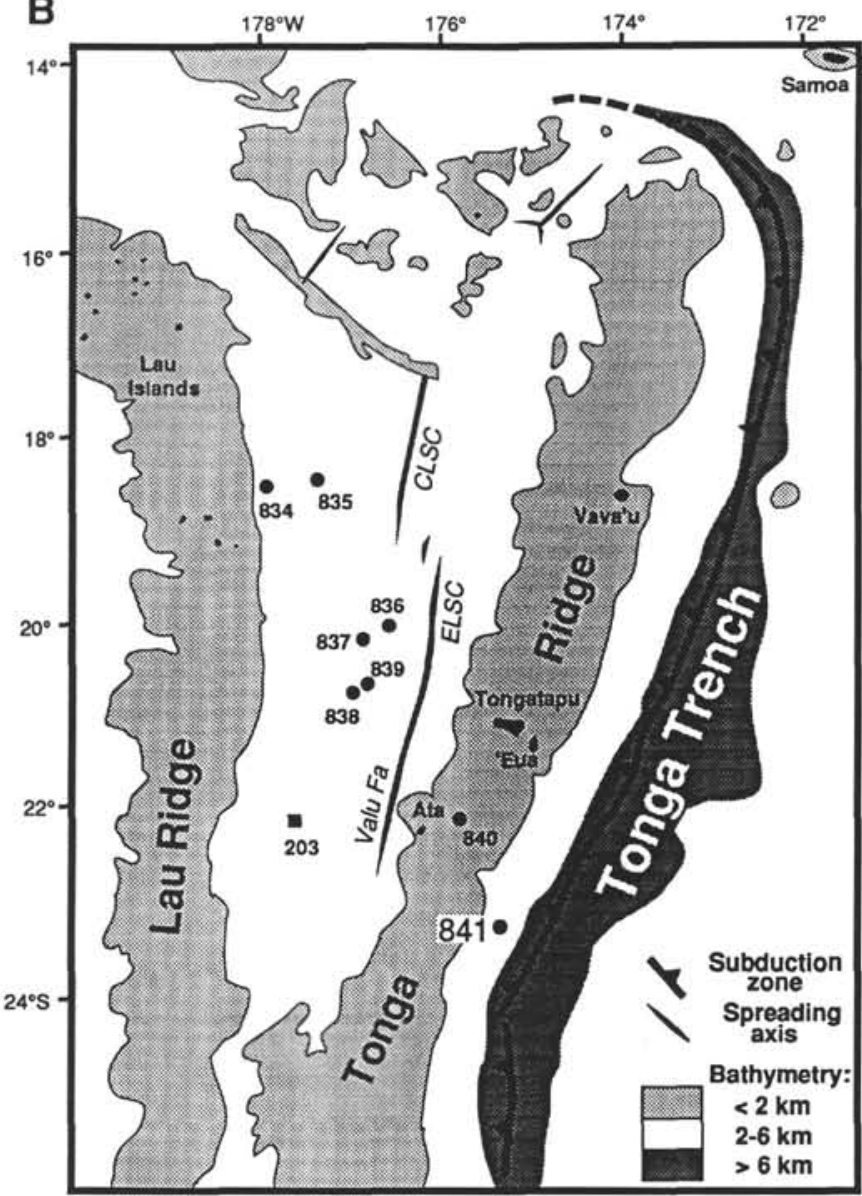

Figure 6. A. Location of the Lau backarc basin. The shaded areas have bathymetries of $<2000 \mathrm{~m}$, and land is shown in black. Active subduction zones are marked with black barbs; inactive subduction zones with white barbs. The area of Figure $6 \mathrm{~B}$ is shown by the box at upper right. B. Detail of the Lau Basin area. The locations of sites drilled on Leg 135 are indicated, together with DSDP Site 203. The data considered in this paper come from Site 841, on the upper trench slope of the Tonga forearc. CLSC $=$ Central Lau Spreading Center, and ELSC $=$ Eastern Lau Spreading Center. 

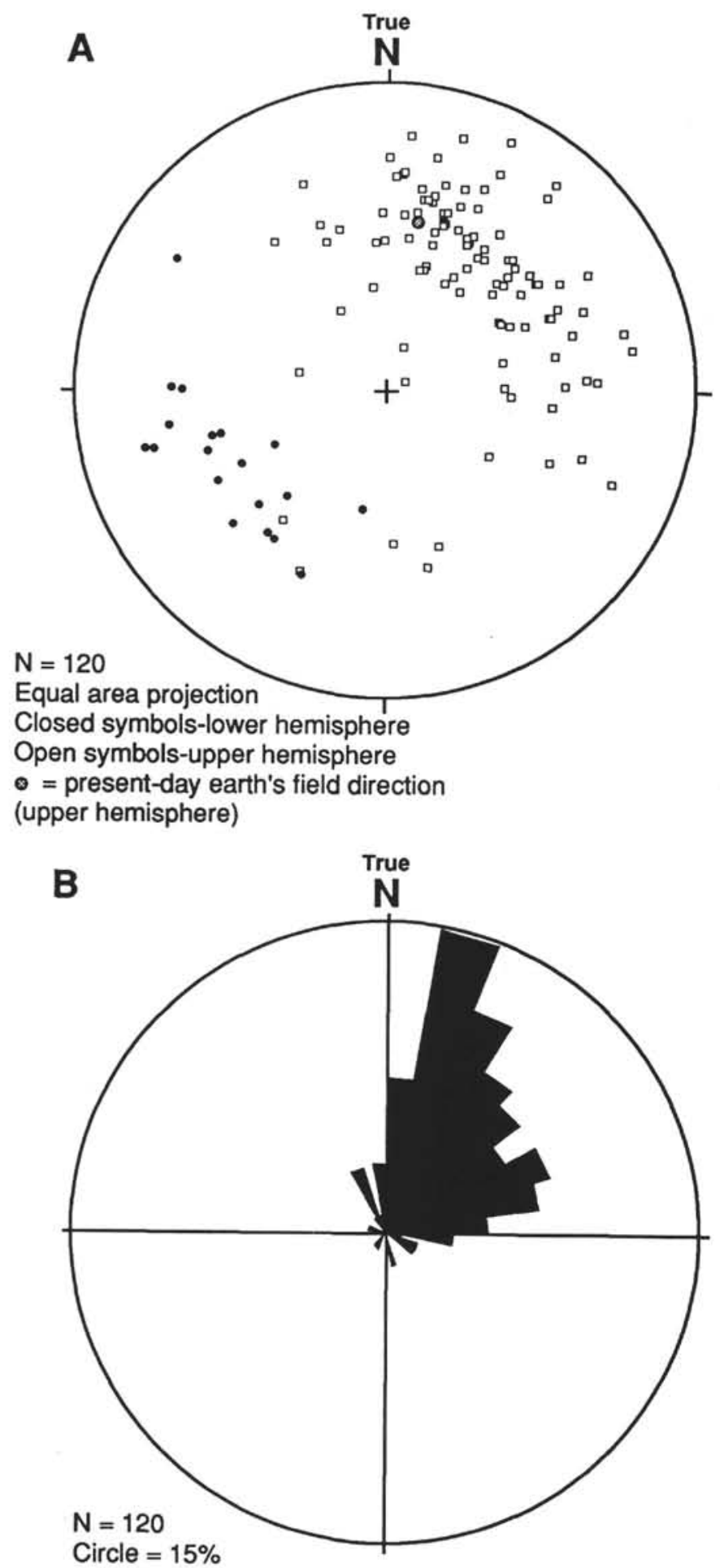

Figure 7. Restored magnetic vectors from Hole 841 B core data. A. Equal area stereographic projection. Note the approximately antipodal directions of reversed polarity samples (lower hemisphere) with respect to normal polarity samples (upper hemisphere). B. Rose diagram of restored declinations, with reverse polarity samples projected through the origin and plotted as if of normal polarity. The restored data show a clear deviation away from the present-day Earth's field direction, and we postulate that this is the consequence of a clockwise rotation of the Tonga Ridge upon opening of the Lau Basin. See text for discussion. $N=$ number of samples. of tectonic processes in a variety of marine environments; for example, in transtensional rift basins, oceanic microplates, and propagating rifts, and in the evolution of oceanic plateaus, or (as illustrated above) island arcs and marginal basins.

\section{ACKNOWLEDGMENTS}

We would like to thank F.J. Vine and C.J. Evans for their careful reviews, and R.B. Whitmarsh and B.J. Murton for comments on an earlier version of this manuscript; M. Rees and N. Brown of SperrySun Drilling Services in Aberdeen, and M. Storms of ODP, for unpublished information and useful discussions on the merits of the modern electronic multishot devices; $\mathrm{N}$. Abrahamsen, for performing some of the sample demagnetizations, and R. Reynolds for processing the FMS data during Leg 135.

\section{REFERENCES}

Adams, J., Bourke, L., and Buck, S., 1990. Integrating Formation MicroScanner images and cores. Oilfield Rev., 2:52-66.

Agar, S.M., 1990. Fracture evolution in the upper ocean crust: evidence from DSDP Hole 504B. In Knipe, R.J., and Rutter, E.H. (Eds.), Deformation Mechanisms, Rheology and Tectonics. Geol. Soc. Spec. Publ. London, $54: 41-50$.

Allerton, S., and Vine, F.J., 1987. Spreading structure of the Troodos ophiolite, Cyprus: some paleomagnetic constraints. Geology, 15:593-597.

Barton, C.A., Tesler, L.G., Zoback, M.D., 1990. Interactive image analysis of borehole televiewer data. In Palaz, I., and Sengupta, S.K. (Eds.), Automated Pattern Recognition in Exploration Geophysics: New York (Springer-Verlag).

Bergosh, J.L., Marks, T.R., and Mitkus, A.F., 1985. New core analysis techniques for naturally fractured reservoirs. Soc. Pet. Eng., Calif. Reg. Mtg., Pap. 13653, 599-610.

Bonhommet, N., Roperch, P., and Calza, F., 1988. Paleomagnetic arguments for block rotations along the Arakapas fault (Cyprus). Geology, 16:422-425.

Borehole Research Group, 1990. Wireline Logging Manual: Palisades, N.Y. (Lamont-Doherty Geological Observatory, Columbia Univ.).

Bourke, L., Delfiner, P., Trouiller, J.-C., Fett, T., Grace, M., Luthi, S., Serra, O., and Standen, E., 1989. Using Formation MicroScanner images. Tech. Rev., 37:16-40.

Collier, J., and Sinha, M., 1990. Seismic images of a magma chamber beneath the Lau Basin back-arc spreading center. Nature, 346:646-648.

Dick, H.J..B., Erzinger, J., Stokking, L.B., et al., 1992. Proc. ODP, Init. Repts., 140: College Station, TX (Ocean Drilling Program).

Eastman Whipstock, 1982. Eastman Whipstock Inc. General Catalogue.

Ekstrom, M.P., Dahan, C., Chen, M.-Y., Lloyd, P., and Rossi, D.J., 1987. Formation imaging with microelectrical scanning arrays. Log Analyst, 28:294-306.

Gillis, K.M., Mével, C., Allan, J.F., et al., in press. Proc. ODP, Init. Repts., 147: College Station, TX, (Ocean Drilling Program).

Goldberg, D., Broglia, C., and Becker, K., 1992. Fracture permeability and alteration in gabbro from the Atlantis II Fracture Zone. In Hurst, A., Griffiths, C.M., and Worthington, P.F. (Eds.), Geological Applications of Wireline Logs II. Geol. Soc. Spec. Publ. London, 65:199-210.

Hawkins, J.W., Bloomer, S.H., Evans, C.A., and Melchior, J.T., 1984. Evolution of intra-oceanic arc-trench systems. Tectonophysics, 102:175-205.

Herzer, R.H., and Exon, N.F., 1985. Structure and basin analysis of the southern Tonga forearc. In Scholl, D.W., and Vallier, T.L. (Eds.), Geology and Offshore Resources of Pacific Island Arcs-Tonga Region. CircumPac. Counc. Energy Miner. Resour., Earth Sci. Ser., 2:55-73.

Karig, D.E., 1970. Ridges and basins of the Tonga-Kermadec island arc system. J. Geophys. Res., 75:239-254.

Kessels, W., and Kück, J., 1992. Computer-aided matching of plane core structures with borehole measurements for core orientation. Sci. Drill., 3:225-238.

\footnotetext{
Abbreviations for names of organizations and publication titles in ODP reference lists follow the style given in Chemical Abstracts Service Source Index (published by
} American Chemical Society). 
Kissel, C., and Laj, C. (Eds.), 1989. Paleomagnetic Rotations and Continental Deformation: Dordrecht (Kluwer Academic Publ.), NATO ASI Series C254.

Knipe, R.J., 1986. Microstructural evolution of vein arrays preserved in Deep Sea Drilling Project cores from the Japan Trench, Leg 57. In Moore, J.C. (Ed.), Structural Fabrics Preserved in Deep Sea Drilling Project Cores from Forearcs. Mem.-Geol. Soc. Am., 166:75-87.

Lehne, K.A., 1990. Fracture detection from logs of North Sea chalk. In Hurst, A., Lovell, M.A., and Morton, A.C. (Eds.), Geological Applications of Wireline Logs. Geol. Soc. Spec. Publ. London, 48:263-271.

Lundberg, N., and Moore, J.C., 1986. Macroscopic structural features in Deep Sea Drilling Project cores from forearc regions. In Moore, J.C. (Ed.), Structural Fabrics Preserved in Deep Sea Drilling Project Cores From Forearcs. Mem.-Geol. Soc. Am., 166:13-44.

McWilliams, M., and Pinto, M.J., 1988. Paleomagnetic results from granitic basement rocks in the Cajon Pass scientific drill hole. Geophys. Res. Lett., 15:1069-1072.

Moore, J.C. (Ed.), 1986. Structural Fabric in Deep Sea Drilling Project Cores from Forearcs. Mem.-Geol. Soc. Am., 166.

Nelson, R.A., Lenox, L.C., and Ward, B.J., 1987. Oriented core: its use, error and uncertainty. AAPG Bull., 71:357-367.

Packham, G.H., 1978. Evolution of a simple island arc: the Lau-Tonga Ridge. Aust. Soc. Expl. Geophys. Bull., 9:133-140.

Parson, L., Hawkins, J., Allan, J., et al., 1992. Proc. ODP, Init. Repts., 135: College Station, TX (Ocean Drilling Program).

Parson, L.M., Pearce, J.A., Murton, B.J., Hodkinson, R.A., Bloomer, S., Ernewein, M., Huggett, Q.J., Miller, S., Johnson, L., Rodda, P., and Helu, S., 1990. Role of ridge jumps and ridge propagation in the tectonic evolution of the Lau back-arc basin, southwest Pacific. Geology, 18:470-473.

Pezard, P.A., and Luthi, S.M., 1988. Borehole electrical images in the basement of the Cajon Pass Scientific Drillhole, California; fracture identification and tectonic implications. Geophys. Res. Lett., 15:1017-1020.

Sager, W.W., Abrahamsen, N., and MacLeod, C.J., 1991. Tectonic rotation of the Tonga Arc, Southwest Pacific, from ODP Leg 135 paleomagnetic data. Eos, 72:541.

Sager, W.W., and Pringle, M.S., 1987. Paleomagnetic constraints on the origin and evolution of the Musicians and South Hawaiian seamounts, central Pacific Ocean. In Keating, B.H., Fryer, P., Batiza, R., and Boehlert, G.W.
(Eds.), Seamounts, Islands and Atolls. Am. Geophys. Union, Geophys. Monogr. Ser., 43:133-162.

Schlumberger, 1986. Dipmeter Interpretation Fundamentals: New York (Schlumberger), SMP-7002.

Schmitz, D., Hirschmann, G., Kessels, W., Kohl, J., Röhr, C., and Dietrich, H.-G., 1989. Core orientation in the KTB pilot well. Sci. Drill., 1:150-155.

Searle, R.C., Rusby, R.I., Engeln, J., Hey, R.N., Zukin, J., Hunter, P.M., LeBas, T.J., Hoffman, H.-J., and Livermore, R., 1989. Comprehensive sonar imaging of the Easter microplate. Nature, 341:701-705.

Serra, O., 1989. Formation MicroScanner Image Interpretation: Houston (Schlumberger Educ. Services), SMP-7028.

Shibuya, H., Merrill, D.L., Hsu, V., and Leg 124 Shipboard Scientific Party, 1991. Paleogene counterclockwise rotation of the Celebes Sea-orientation of ODP cores utilizing the secondary magnetization. In Silver, E.A., Rangin, C., von Breymann, M.T., et al., Proc. ODP, Sci. Results, 124: College Station, TX (Ocean Drilling Program), 519-526.

Sperry-Sun, 1991. ESS-Electronic Core Orientation: Aberdeen, Scotland (Sperry-Sun Drilling Services).

Taira, A., Hill, I., Firth, J.V., et al., 1991. Proc. ODP, Init. Repts., 131: College Station, TX (Ocean Drilling Program).

Tamaki, K., and Larson, R.L., 1988. The Mesozoic tectonic history of the Magellan Microplate in the western central Pacific. J. Geophys. Res. 93:2857-2874.

Tarling, D.H., 1983. Palaeomagnetism, Principles and Applications in Geology, Geophysics and Archaeology: London (Chapman and Hall).

Teufel, L.W., 1982. Prediction of hydraulic fracture azimuth from anelastic strain recovery measurements of oriented core. In Goodman, R., and Heuze, F. (Eds.), Issues in Rock Mechanics. Proc. 23rd U.S. Natl. Rock Mech. Symp., 238-246.

Zemanek, J., Glenn, E.E., Norton, L.J., and Caldwell, R.L., 1970. Formation evaluation by inspection with the borehole televiewer. Geophysics, $35: 254-269$.

Date of initial receipt: 2 July 1992

Date of acceptance: 25 March 1993

Ms 135SR-160 

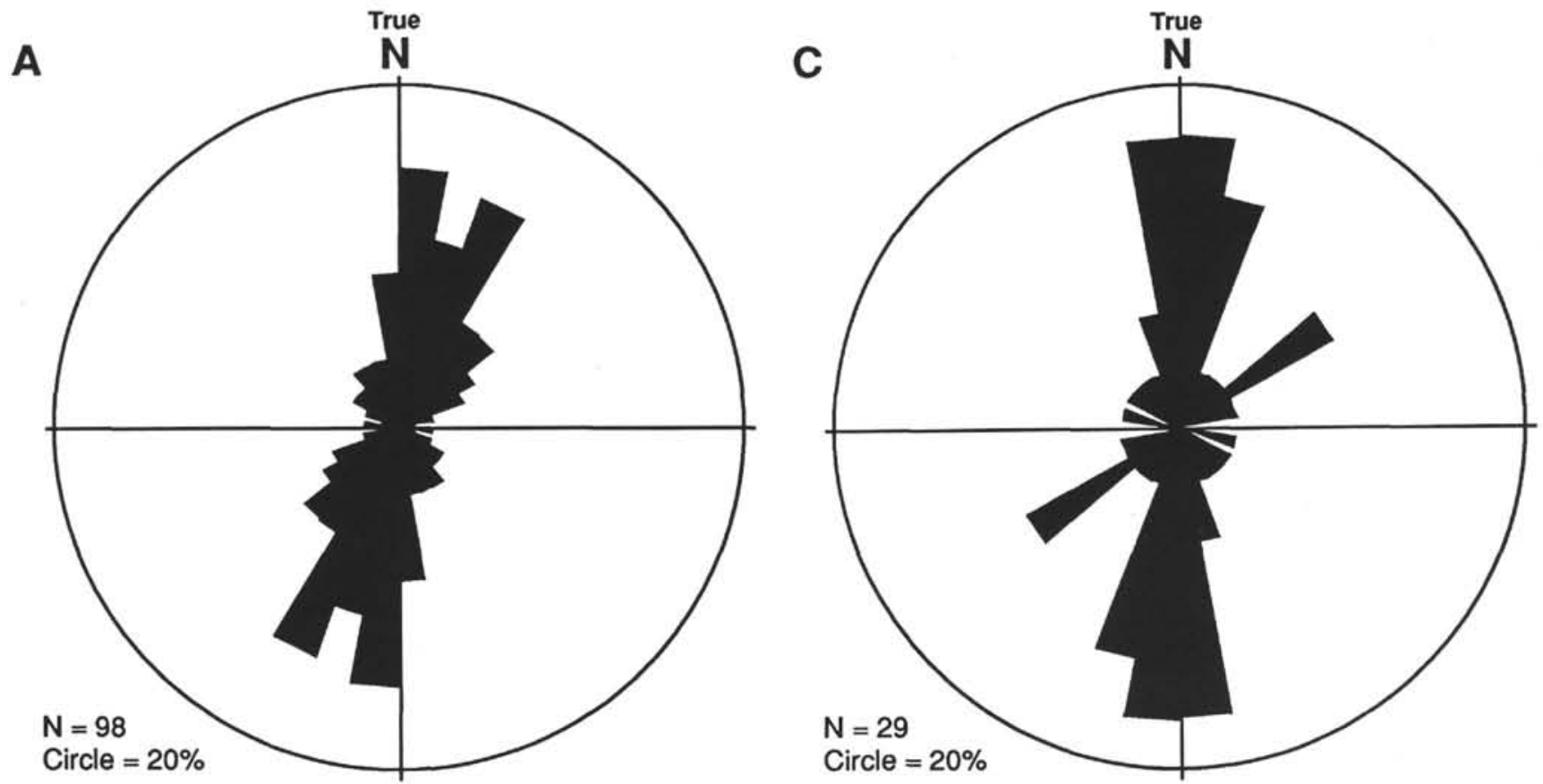

B

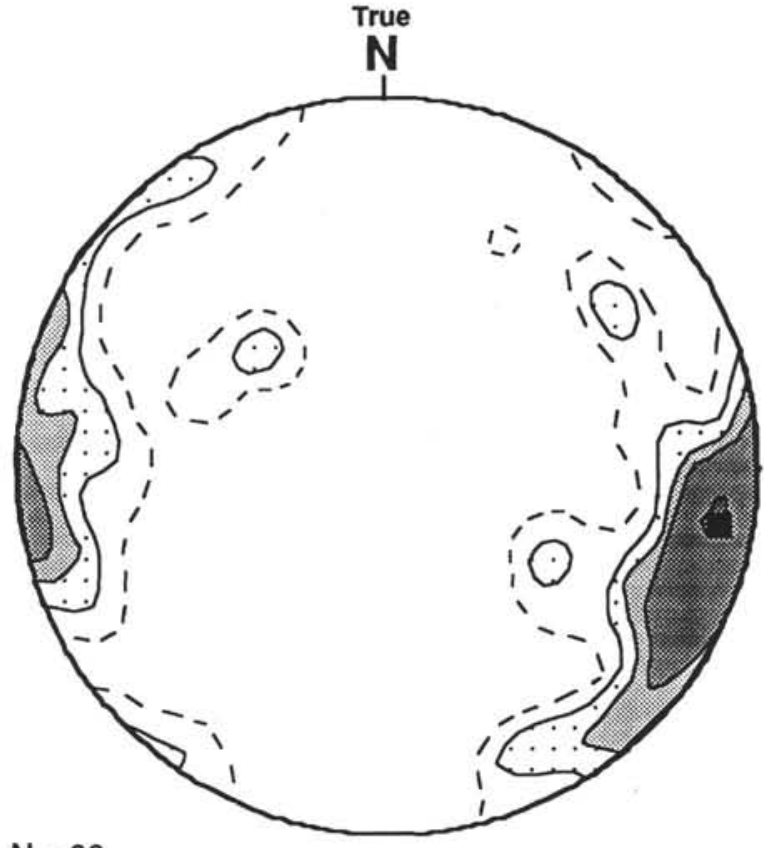

$N=98$

Maximum density $=12.1 \%$

Contour intervals $=1,2,3,4$ and $8 \%$

Lower hemisphere equal area projection

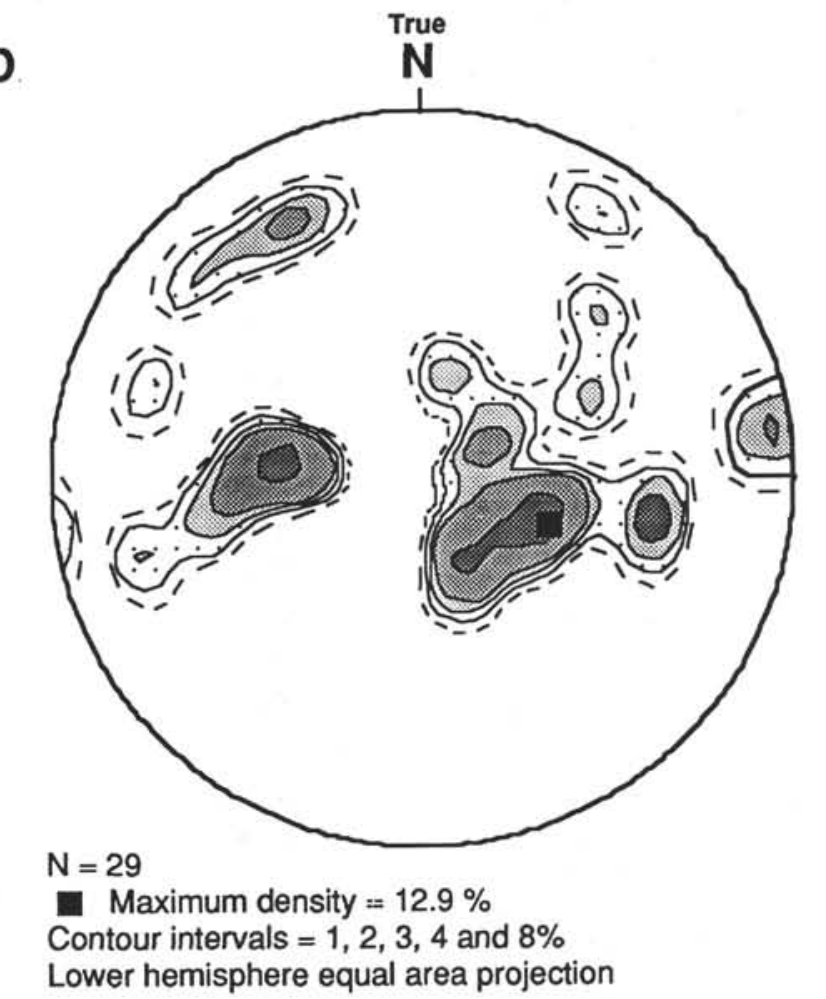

Figure 8. Restored faults from Hole 841B core data. A. Rose diagram of the strikes of normal fault planes. B. Contoured lower hemisphere equal area projections of poles to normal fault planes. C. Rose diagram of the strikes of reverse fault planes. D. Contoured lower hemisphere equal-area projections of poles to reverse fault planes. Note the preferred trend parallel to the strike of the Tonga Trench (Fig. 6B), and the significantly shallower dip of the reverse faults than the normal faults. The tectonic implications of the data are discussed by MacLeod (this volume). $N=$ number of samples. 